\title{
Studying faculty members' readiness to use Shaqra University e-learning platform
}

\author{
Raed Alotaibi ${ }^{1}$, Abdulrahman Alghamdi ${ }^{2}$ \\ ${ }^{1}$ Shaqra Community College, Shaqra University, Kingdom of Saudi Arabia \\ ${ }^{2}$ College of Computing and Information Technology, Shaqra University, Kingdom of Saudi Arabia
}

\begin{tabular}{l}
\hline Article Info \\
\hline Article history: \\
Received Jan 20, 2021 \\
Revised Jun 6, 2021 \\
Accepted Jun 13, 2021 \\
\hline
\end{tabular}

\section{Keywords:}

Computer science

E-learning platforms

Information systems

Shaqra University's readiness,

gender, and usage experience

\begin{abstract}
In Saudi Arabia, most universities are seeking to implement e-learning to improve education access and processes. Although some universities have already implemented e-learning, most have not. Shaqra University is aiming to implement an e-learning system. Therefore, through the use of a questionnaire, this study examines faculty members' readiness to use the elearning platform and assesses their readiness based on gender differences and user experience. Factors considered were usage self-efficacy, self-confidence in dealing with e-learning, Attitude towards e-learning and educational needs towards e-learning. The results revealed that, based on all these factors, faculty members were ready to use the platform of e-learning. There were no differences between male and female participants in self-efficacy in using information and communications technology, self-confidence in e-learning and educational needs towards e-learning. The females' mean score was significantly higher than the males' mean score. Between faculty members with no experience and faculty members' who were experienced in e-learning, user experience was significantly different for self-efficacy of using information and communications technology, self-confidence in e-learning and attitude towards e-learning. These results revealed that faculty members are ready to use a platform of e-learning and these results may help decision makers in Shaqra University to successfuly adopt an e-learning platform.
\end{abstract}

This is an open access article under the CC BY-SA license.

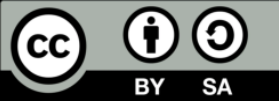

\section{Corresponding Author:}

Abdulrahman Alghamdi

College of Computing and Information Technology

Shaqra University

Kingdom of Saudi Arabia

Email: alghamdia@su.edu.sa

\section{INTRODUCTION}

E-learning is defined as "education that uses computerised communication systems as an environment for communication, the exchange of information, and interaction between students and instructors" [1]. Usage of e-learning is a common method of delivering education to university students and has many benefits for students, academic staff and universities [2]. Nowadays, e-learning systems are widely used by all educational systems [3]. E-learning systems help universities to provide learning and to manage and plan educational processes in order to deliver it in an effective way [4]. E-learning enhances educational outcomes and productivity as students can use it anywhere and anytime [5]. In [6] stated that e-learning is better than traditional methods because it increases the efficiency and effectiveness of learning and encourages students to innovate. E-learning platforms have many advantages such as increasing students' focus on learning, less withdrawal from studying, improving students' academic results and enabling students to acheive their academic goals [7]. 
Shaqra University in Saudi Arabia was established 2009 and has more than 30,000 students and 24 colleges. Until now, Shaqra University has not adopted any e-learning systems in its educational processes. Therefore, the decision makers in Shaqra University aim to reap the benefits of e-learning by adopting an e-learning platform, the Shaqra University platform, which includes mobile learning, virtual classrooms, analytic reports, a learning objects repository (LOR), a learning management system (Moodle) and an ePortfolio [8]. Whilst initiated with good intentions, many e-learning projects fail to be adopted. There are many reasons associated with these failed projects, however, the most important factor identified is that stakeholders are not ready to adopt the system. In other words, managers start using e-learning systems without preparing all stakeholders and users for the system's uptake [2], [9]. E-learning readiness indicates the institution's readiness to use and implement the e-learning project. Technological readiness plays a key role in the effective and efficient use of e-learning systems [10]. Almaiah and Masita [11] recommended that carefully considering and assessing readiness encourages universityes to the effective adoption of mobile learning. A study by [12] found that technological readiness played a key role in the succussful adoption of e-learning in Saudi Arabia. A lack of assessment of institutional readiness is also a key issue associated with failed e-learning system adoption [10]. According to [4], the three previous studies found that university readiness, including students' readiness, faculty readiness and institutional readiness, are key factors in the failure of e-learning adoption in universities. A more recent study by [13] claimed that readiness for e-learning plays a key role and has a significant impact on learning.

Gender and experience significantly influence technology adoption and acceptance in Arab countries [14], [15]. A study examining the influence of gender on the e-learning readiness of Hong Kong's primary and secondary school in-service and trainee teachers indicated that males were better at using information and communication technology (ICT) than females [16]. Differences have also been shown between female and male students regarding their satisfaction with e-learning activities in two European universities [17]. A recent study about e-learning adoption and acceptance in Pakistan showed that female students are more susceptible to social influence and more anxious than male students [18]. Previous studies have found differences between less experienced users and more experienced users regarding societal impact to accept new technologies [19]. A more recent study found that, in Pakistan, less experienced students were more impacted by social influences than more experienced students in relation to e-learning adoption and acceptance [18].

This study uses four factors identified in a previous study [2] to measure faculty members' readiness to use the e-learning platform in Shaqra University, namely, self-efficacy of using ICT, self confidence in dealing with e-learning, attitude towards e-learning and educational needs towards e-learning (Figure 1). The definition of educational needs towards e-learning readiness is "one's perception of his/her educational requirements in e-learning along with one's colleagues' needs". Self-efficacy of usage towards ICT is defined as "the degree to which one believes in his/her ability to use basic computer programs and internet tools". Attitude towards using e-learning refers to "one's reactions towards e-learning, intention to use it, and opinion on whether it is beneficial or not". The definition of self-confidence in dealing with e-learning is "one's perception pertaining to having more advanced e-learning-related abilities and knowledge such as using learning/content management systems and software and to create e-learning material" [2].

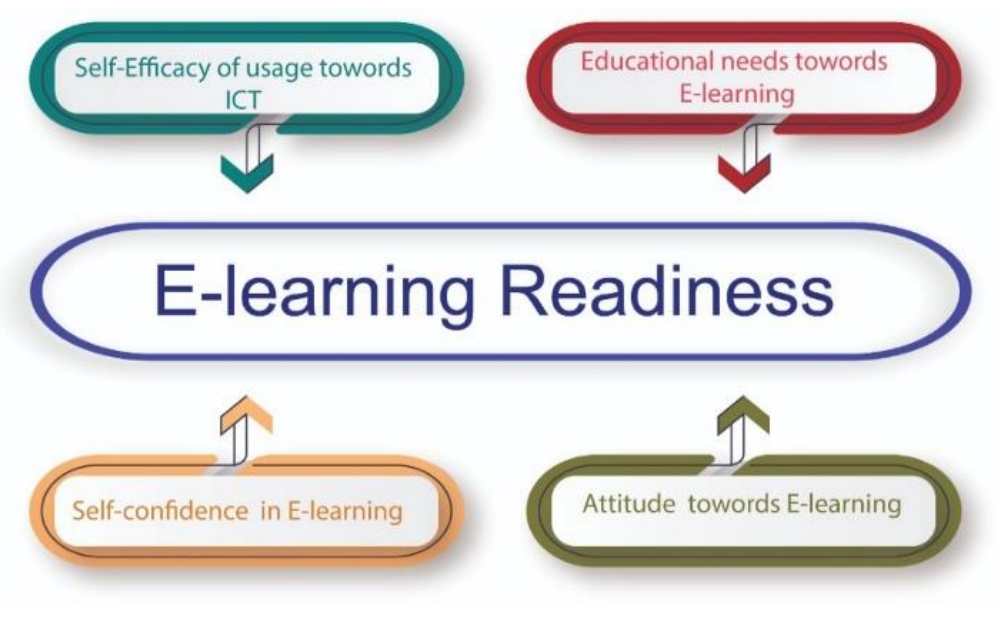

Figure 1. Conceptual framework for this study 
To conclude this discussion of the research problem, until now there have been no e-learning systems used in educationl processes in Shaqra University. Shaqra University is now seeking to adopt an e-learning system called the Shaqra University platform for e-learning. Based on a review of the literature, the assessment of readiness of stakeholders is an important factor to consider in the adoption and use of any electronic system. Because the absence of an assessment of institutional readiness is also a key issue that is associated with failed e-learning system adoption [10], it is very important to examine the acceptance of new systems to facilitate their successful implementation [4], [20]. Therefore, as faculty members have a key role in successfully implementing e-learning, this study aims to assess their readiness to use an e-learning platform in Shaqra University. The study will also examine the effects of gender differences and diffences in usage experience on faculty members' readiness to use the e-learning platform. More specifically, the research questions are: i) Are faculty members ready to use the platform e-learning in Shaqra University?; ii) Are there any differences between female and male faculty members' readiness to use the e-learning platform in Shaqra University?; iii) Are there any differences between faculty members' who have never experienced e-learning and faculty members' who are experienced regarding their readiness to use the e-learning platform at Shaqra University?

\section{METHODOLOGY}

This study adopted a quantitative method by adopting an online questionnaire. A questionnaire was used to collect the data as it is a cost-effective, efficient and appropriate tool to reach female and male participants [21]. As the ducation system in Saudi Arabia is gender separated, a questionnaire was considered to be an appropriate method to collect data from male and female faculty members.

\subsection{Questionniare}

The questionnaire used in this study to collect data was validated and utilized by previous studies such as [2] and it was modified slightly in phrases to suit the study aims. As the majourity of the target population were native Arabic speakers, the questionnaire was translated into Arabic, and it was validated by three experts of translation in order to avoid wording issues. The questionnaire has three parts. Part 1 contains the general information about the study and instructions on how to complete the questionnaire. It also includes ethical information, to obtain consent from the participants. Part 2 relates to the demographic data of the participants. Part 3 measures the faculty members' readiness to use the e-learning platform via four factors: self-efficacy of usage towards ict, self confidence in e-learning, attitude towards e-learning and educational needs towards e-learning. Each of the factors was scored on a five-point likert scale ( $5=$ strongly agree (strongly ready), $4=$ agree (ready), $3=$ neutral (moderate), $2=$ disagree (not ready) and 1=strongly disagree (strongly not ready)).

\subsection{Participants and sampling technique (data collection)}

In this study, faculty members in Shaqra University in all departments were the target population. Random sampling was used to collect data to generalize the results to the whole population [22]. The questionnaire was made available to faculty members on the $10^{\text {th }}$ of February 2020 . To ensure all faculty members could be reached and that the questionnaire was available to all of them, the researcher sent the link to the questionnaire to the Deans of each college to distribute to the faculty members in two sections (male and female). More than 400 questionnaires were distributed and 128 were returned with full responses.

\subsection{Analysis tests}

To analyse the data, the researchers analysed the data using SPSS Statistics version 25. Firstly, demographic data was ananlysed using frequencies of descriptive statistics. Then, the researchers measured the instrument consisitney using Cronbach's alpha test. After that, the resrachers used a mean score statistic and standard deviation (see Table 1) as used in a previous studies [23]. Also, T-tests were used to analyse the differences in gender and usage experience of faculty members' readiness to use the e-learning platform.

Table 1. Interpretation of faculty members' readiness to use the e-learning platform [23]

\begin{tabular}{cc}
\hline Mean Score Range & Interpretation of Readiness \\
\hline 1.00 to $\leq 1.80$ & Strongly Not Ready \\
$>1.80$ to $\leq 2.61$ & Not Ready \\
$>2.61$ to $\leq 3.41$ & Neutral \\
$>3.41$ to $\leq 4.21$ & Ready \\
$>4.21$ to $\leq 5.00$ & Strongly Ready \\
\hline
\end{tabular}




\section{RESULTS}

\subsection{Characteristics of participants}

As seen in Table 2, the majority of participants, 90 (70.3\%), were male. Most participants, 67 (52.3\%), were assistant professors, lecturers, 25 (19.5\%) and associate professors, 18 (14.1\%). Most participants were non-Saudi, 77 (60.2\%), with 51 Saudi participants. Most participants had experience with e-learning, 103 $(80.5 \%)$, while $25(19.5 \%)$ were inexperienced.

Table 2. Characteristics of participants

\begin{tabular}{llcc}
\hline \multicolumn{2}{c}{ Information } & Number of participants & Percentage of sample \\
\hline \multirow{4}{*}{ Gender } & Male & 90 & 70.3 \\
& Female & 38 & 29.7 \\
& Total & 128 & 100.0 \\
\multirow{5}{*}{ Academic ranking } & Professor & 18 & 3.9 \\
& Associate Professor & 67 & 14.1 \\
& Assistant Professor & 25 & 52.3 \\
& Lecturer & 13 & 19.5 \\
& Teaching Assistant & 128 & 10.2 \\
& Total & 51 & 100.0 \\
& Saudi & 77 & 39.8 \\
& Non-Saudi & 128 & 60.2 \\
& Total & 103 & 100.0 \\
& Yes & 25 & 80.5 \\
& No & 128 & 19.5 \\
& Total & & 100.0 \\
\hline
\end{tabular}

\subsection{Survey instrument reliability}

Cronbach's alpha is used to assess the strength of instrument consistency [24]. According to [25] the acceptable value of Cronbach's alpha should be more than 0.70. Based on the results in Table 3, all Cronbach's alpha reliability coefficients for each group were greater than 0.70 and the overall reliability for this instrument was 0.947 , which is considered excellent. Therefore, the results of this study can be considered reliable.

Table 3. Cronbach's alpha reliability coefficient for the survey questionnaire

\begin{tabular}{lcc}
\hline \multicolumn{1}{c}{ Section } & Number of items & Cronbach alpha value \\
\hline Self-Efficacy of usage towards ICT & 5 & 0.894 \\
Self confidence in e-learning & 10 & 0.923 \\
Attitude towards e-learning & 14 & 0.963 \\
Educational needs towards e-learning & 4 & 0.840 \\
Total & 33 & 0.956 \\
\hline
\end{tabular}

\subsection{Faculty members' readiness}

Faculty members who participated in this study were ready to use an e-learning platform in Shaqra University (Table 4). The rankings were as follows: self-efficacy of usage towards ICT (SE) > educational needs towards e-learning $(\mathrm{EN})>$ attitude towards e-learning (AT) $>$ self confidence in e-learning (SC). Self-efficacy of usage towards ICT was rated as being ready (Table 5). The item 'I can use search engines (Google) with confidence' had the highest mean value, while 'I can solve problems that I encounter during computer use' had the lowest mean. Self confidence in e-learning (SC) was rated as being ready, although some items were neutral (Table 6). The item 'I can access online libraries and resources' had the highest mean, while 'I can design a Web page' had the lowest mean.

Table 4. Faculty members' readiness to use the e-learning platform $(\mathrm{N}=128)$

\begin{tabular}{lcc}
\hline \multicolumn{1}{c}{ Category } & Mean & Standard deviation \\
\hline Self-Efficacy of usage towards ICT (SE) & 4.48 & 0.676 \\
Self confidence in e-learning (SC) & 3.55 & 0.834 \\
Attitude towards e-learning (AT) & 3.71 & 0.868 \\
Educational needs towards e-learning (EN) & 4.27 & 0.770 \\
Overall & 4.0025 & 0.784 \\
\hline
\end{tabular}


Table 5. Participant self-evaluation of self-efficacy of usage towards ICT $(\mathrm{N}=128)$

\begin{tabular}{lcc}
\hline \multicolumn{1}{c}{ Self-Efficacy of usage towards ICT } & Mean & Standard deviation \\
\hline I can use the computer with confidence & 4.59 & 0.758 \\
I can use office programs (Power Point, Word and Excel) with confidence & 4.62 & 0.722 \\
I can safely use web browsers (Internet Explorer, Google and Chrome) & 4.56 & 0.858 \\
I can use search engines (Google) with confidence & 4.67 & 0.677 \\
I can solve problems that I encounter during computer use & 3.97 & 0.980 \\
Overall & 4.482 & 0.799 \\
\hline
\end{tabular}

Table 6. Participant self-evaluation of self confidence in e-learning $(\mathrm{N}=128)$

\begin{tabular}{lcc}
\hline \multicolumn{1}{c}{ Self confidence in e-learning } & Mean & Standard deviation \\
\hline I have knowledge about e-learning & 3.93 & 1.005 \\
I have the knowledge and skills to prepare e-learning materials & 3.77 & 1.013 \\
I can use content management software (Blackboard and Moodle) with confidence & 3.63 & 1.093 \\
I can design a Web page & 2.88 & 1.217 \\
I can use software that will prepare e-learning materials (Photoshop, Publisher, and Camtasia) & 3.10 & 1.209 \\
I can manage online forums & 3.27 & 1.126 \\
I can develop guidelines for e-learning to benefit students & 3.52 & 1.027 \\
I know the legal issues related to e-learning (copyright and privacy) & 3.51 & 1.177 \\
I can access online libraries and resources & 4.06 & 0.858 \\
I feel ready to use e-learning in my teaching activities & 3.85 & 1.095 \\
Overall & 3.55 & 0.834 \\
\hline
\end{tabular}

Attitude towards e-learning was rated as being ready, although one item was neutral (Table 7). The item 'I think I will not be nervous when studying through e-learning' had the highest mean, while 'I believe that e-learning will be more effective than traditional classroom education' had the lowest mean. The factor, educational needs towards e-learning was rated as being ready (Table 8). The item 'University administrators need training on e-learning' had the highest mean, while 'I need training on e-learning' had the lowest mean.

Table 7. Participant self-evaluation of attitude towards e-learning $(\mathrm{N}=128)$

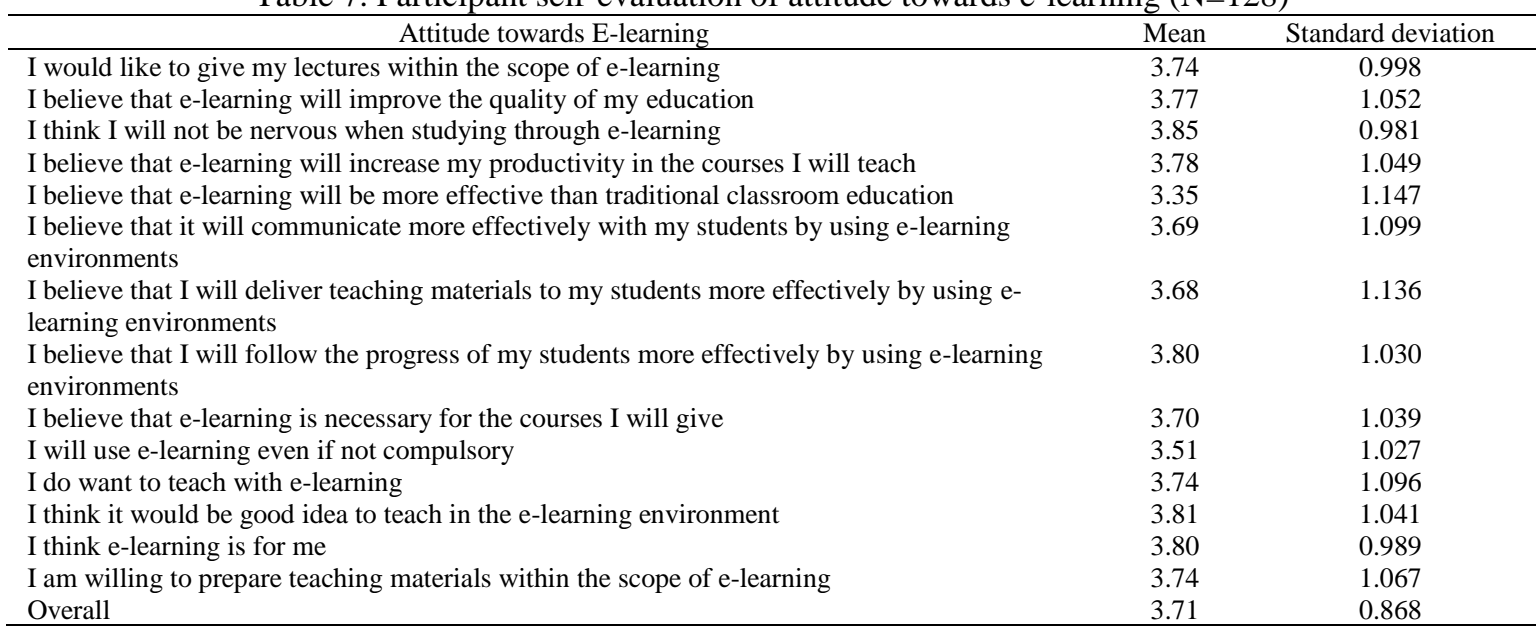

Table 8. Participant self-evaluation of educational needs towards e-learning $(\mathrm{N}=128)$

\begin{tabular}{lcc}
\hline \multicolumn{1}{c}{ Educational needs towards E-learning } & Mean & Standard deviation \\
\hline I need training on e-learning & 3.95 & 1.082 \\
My students need training in e-learning & 4.41 & 0.901 \\
Other faculty members in the department need training on e-learning & 4.30 & 0.892 \\
University administrators need training on e-learning & 4.42 & 0.857 \\
Overall & 4.27 & 0.770 \\
\hline
\end{tabular}

\subsection{Difference of gender groups and usage experience groups on faculty members' readiness to use an e-learning platform at Shaqra University}

\subsubsection{Gender}

The results of the T-test analysis presented in Table 9 show that self-efficacy of usage towards ICT was rated as strongly ready for both males and females who participated in this study. They also show that, 
although the females' mean score was higher than the males' mean score, the difference in readiness between males and females was not significant. Self-confidence in e-learning was rated as ready for both males and females who participated in this study (Table 10). The difference in readiness between males and females was not significant.

Attitude towards e-learning was rated as ready for both males and females who participated in this study (Table 11). The females' mean score was significantly higher than the males' mean score, suggesting females had a better attitude towards e-learning. The factor as shown in (Table 12), educational needs towards e-learning was rated as strongly ready for both males and females who participated in this study. Although the females' mean score was higher than the males' mean score, the difference in readiness between males and females was not significant.

Table 9. Readiness based on gender and self-efficacy of usage towards ICT

\begin{tabular}{cccccccc}
\hline \multicolumn{3}{c}{ Female } & \multicolumn{5}{c}{ Male } \\
$\mathrm{N}$ & Mean & SD & $\mathrm{N}$ & Mean & $\mathrm{SD}$ & $\mathrm{T}$ & $\mathrm{P}$ \\
\hline 38 & 4.54 & 0.487 & 90 & 4.46 & 0.742 & -0.660 & 0.510 \\
\hline
\end{tabular}

Table 10. Readiness based on gender and self-confidence in e-learning

\begin{tabular}{cccccccc}
\hline \multicolumn{3}{c}{ Female } & \multicolumn{5}{c}{ Male } \\
$\mathrm{N}$ & Mean & $\mathrm{SD}$ & $\mathrm{N}$ & Mean & $\mathrm{SD}$ & $\mathrm{T}$ & $\mathrm{P}$ \\
\hline 38 & 3.55 & 0.848 & 90 & 3.55 & 0.812 & 0.044 & 0.965 \\
\hline
\end{tabular}

Table 11. Readiness based on gender and attitude towards e-learning

\begin{tabular}{|c|c|c|c|c|c|c|c|}
\hline \multicolumn{3}{|c|}{ Female } & \multicolumn{3}{|c|}{ Male } & \multirow{2}{*}{$\mathrm{T}$} & \multirow{2}{*}{$\mathrm{P}$} \\
\hline $\mathrm{N}$ & Mean & SD & $\mathrm{N}$ & Mean & SD & & \\
\hline 38 & 4.01 & 0.741 & 90 & 3.59 & 0.891 & -2.572 & 0.011 \\
\hline
\end{tabular}

Table 12. Readiness based on gender and educational needs towards e-learning

\begin{tabular}{cccccccc}
\hline \multicolumn{3}{c}{ Female } & \multicolumn{5}{c}{ Male } \\
$\mathrm{N}$ & Mean & $\mathrm{SD}$ & $\mathrm{N}$ & Mean & $\mathrm{SD}$ & $\mathrm{T}$ & $\mathrm{P}$ \\
\hline 38 & 4.39 & 0.739 & 90 & 4.22 & 0.781 & -1.178 & 0.241 \\
\hline
\end{tabular}

\subsubsection{Usage experience}

The results of the T-test analysis presented in Table 13 show that self-efficacy of usage towards ICT was rated as ready for all faculty members regardless of experience with e-learning. The experienced group's mean score was significantly higher than the non-experienced group's mean score. Self confidence in e-learning was rated as ready for experienced faculty members and as neutral for faculty members with no experience (Table 14). The difference in readiness between experienced faculty members and those with no experience was significant.

Attitude towards e-learning was rated as ready for experienced faculty members and neutral for faculty members with no experience (Table 15). The difference in readiness between experienced faculty members and those with no experience was significant. The factor, educational needs towards e-learning was rated as ready for experienced faculty members', and strongly ready for faculty members' who had no experience (Table 16). Although the mean score was higher for the non-experienced group than the experienced group, the difference was not significant.

Table 13. Readiness based on usage experience and self-efficacy of usage towards ICT

\begin{tabular}{cccccccc}
\hline \multicolumn{3}{c}{ Female } & \multicolumn{5}{c}{ Male } \\
$\mathrm{N}$ & Mean & SD & $\mathrm{N}$ & Mean & SD & $\mathrm{T}$ & $\mathrm{P}$ \\
\hline 25 & 2.74 & 0.823 & 103 & 3.75 & 0.713 & 6.128 & 0.000 \\
\hline
\end{tabular}

Table 14. Readiness based on usage experience and Self-confidence in e-learning

\begin{tabular}{cccccccc}
\hline \multicolumn{3}{c}{ Female } & \multicolumn{5}{c}{ Male } \\
$\mathrm{N}$ & Mean & $\mathrm{SD}$ & $\mathrm{N}$ & Mean & $\mathrm{SD}$ & $\mathrm{T}$ & $\mathrm{P}$ \\
\hline 25 & 3.18 & 0.827 & 103 & 3.84 & 0.832 & 3.548 & 0.001 \\
\hline
\end{tabular}


Table 15. Readiness based on usage experience and attitude towards e-learning

\begin{tabular}{cccccccc}
\hline \multicolumn{3}{c}{ Female } & \multicolumn{5}{c}{ Male } \\
$\mathrm{N}$ & Mean & SD & $\mathrm{N}$ & Mean & SD & $\mathrm{T}$ & $\mathrm{P}$ \\
\hline 25 & 3.18 & 0.827 & 103 & 3.84 & 0.832 & 3.548 & 0.001 \\
\hline
\end{tabular}

Table 16. Readiness based on usage experience and educational needs towards e-learning

\begin{tabular}{cccccccc}
\hline \multicolumn{3}{c}{ Female } & \multicolumn{5}{c}{ Male } \\
$\mathrm{N}$ & Mean & SD & $\mathrm{N}$ & Mean & SD & $\mathrm{T}$ & $\mathrm{P}$ \\
\hline 25 & 4.53 & 0.579 & 103 & 4.21 & 0.800 & -1.889 & 0.061 \\
\hline
\end{tabular}

\section{DISCUSSION}

Faculty members who participated in this study were generally ready to use the proposed e-learning platform in Shaqra University. More specifically, the results revealed that self-efficacy of usage towards ICT had the highest mean score (the greatest influence on readiness), while self-confidence in e-learning had the lowest mean score (the lowest influence on readiness). This result contradicts those of many studies such as [26], [27] which found that Educational needs towards e-learning had the greatest influence on readiness to use e-learning. However, our result is supported by [2] who found that self-efficacy of usage towards ICT had the highest mean score, and self-confidence in e-learning had the lowest mean score in Hacettepe University in Turkey. These results suggest that Shaqra University will face few staff readiness issues in using the platform. They also indicate that faculty members are able to use basic computer programs and internet tools. In addition, these results show that the faculty members are aware of and able to use learning/content management systems and software and create e-learning material. Faculty members have a positive attitude towards and intention to use the platform because they believe that it is a good idea. As this factor is important in using an e-learning platform successfully, Shaqra University should make available awareness courses and seminars about this project in order to improve attitudes toward using the platform. These results may also indicate that faculty members have not enough confidence to use an e-learning platform, so Shaqra University should develop specific programs, such as an awareness program, in order to increase their confidence in using e-learning. These results also showed that faculty members scored highly on self-efficacy of usage towards ICT, indicating that they will face difficulties in using an e-learning platform because they have adequate technical skills. However, Shaqra University should make training courses available to faculty members to ensure they are ready to use the technical aspects of an e-learning platform. Finally, faculty members have sufficient knowledge about educational requirements in e-learning. However, Shaqra University should conduct some awareness workshops and training sessions to make sure that all faculty members are not only ready to use the platform but that they are also encouraged to use it.

There were no differences between males and females in the factors of self-efficacy of usage towards ICT, self confidence in e-learning, and educational needs towards e-learning. These results indicate that generally males and females have the same readiness to use the new e-learning platform. There were significant differences between males and females in the factor of Attitude towards e-learning. This result indicates that the females' mean score was higher than the males' mean score, suggesting that females had a better attitude towards e-learning. This was supported by [28], who found a significant difference between males and females in their attitudes towards using an e-learning platform, with females having better attitudes in two different universities in Spain and Chile. As expected, our results revealed that there was a significant difference in selfconfidence in e-learning and self-efficacy of usage towards ICT between faculty members with no experience and faculty members who were experienced e-learning users, with higher scores for experienced users. This result indicates that the experienced faculty members had more knowledge of and better ability with learning/content management systems, software and creation of e-learning material than faculty members' with no experience. The results also revealed that experienced faculty members have a more positive attitude toward using e-learning than faculty members with no experience because they have already obtained the benefits and believe that using e-learning is a good idea. This result was supported by [12], who found that attitude towards e-learning was rated as ready for experienced faculty members. There was no difference in educational needs towards e-learning between experienced faculty members and those with no experience.

\section{CONCLUSION}

This study aimed to measure faculty members' readiness to use an e-learning platform and to assess the differences between males and females and users with different levels of experience with e-learning. The results revealed that the faculty members who participated in this study were ready to use an e-learning platform in Shaqra University based on several factors. The readiness factors were ranked as follows: self-Efficacy of 
usage towards ICT (SE)>educational needs towards e-learning (EN)>attitude towards e-learning (AT) $>$ self confidence in e-learning (SC). There were few differences between males and females but user experience did make a difference on self-efficacy of use of ICT, self-confidence in e-learning, and Attitude towards e-learning. Most of these results are supported by previous studies which were discussed above and these may be reasonable results given the big revolution in technology in Saudi society. The results of this study indicate that faculty members need some training courses in e-learning in order to increase their confidence in elearning, given that the factor of self-confidence in e learning scored the lowest. This study may make a practical contribution to knowledge by providing information to help decision makers in Shaqra University successfully implement an e-learning platform. The factors used in this study may be used in other contexts to assess faculty members' readiness to adopt e-learning systems.

\section{REFERENCES}

[1] A. Sangrà, D. Vlachopoulos, and N. Cabrera, "Building an inclusive definition of e-learning: An approach to the conceptual framework," The International Review of Research in Open and Distributed Learning, vol. 13, no. 2, Apr. 2012, doi: 10.19173/irrodl.v13i2.1161.

[2] Ö. Demir and H. Yurdugül, "Investigation of Effect Of E-Learning Readiness Levels of Academic Staff on those of Universities," in International Business \& Education Conferences, 2015. The Clute Institute, New York City, NY, USA, 2015, pp. 258-259.

[3] M. A. Almaiah, M. A. Jalil, and M. Man, "Extending the TAM to examine the effects of quality features on mobile learning acceptance," Journal of Computers in Education, vol. 3, no. 4, pp. 453-485, Aug. 2016, doi: 10.1007/s40692-016-0074-1.

[4] M. A. Almaiah, A. Al-Khasawneh, and A. Althunibat, "Exploring the critical challenges and factors influencing the E-learning system usage during COVID-19 pandemic," Education and Information Technologies, vol. 25, May 2020, doi: 10.1007/s10639-020-10219-y.

[5] J. Lee, H. D. Song, and A. Hong, "Exploring Factors, and Indicators for Measuring Students' Sustainable Engagement in e-Learning," Sustainability, vol. 11, no. 4, pp. 1-12, Feb. 2019, doi: 10.3390/su11040985.

[6] N. W. A. Majid, T. Ridwan, A. Fauzi, and R. Hikmawan, "Integrating of E-learning to Improve Students Competence in Vocational School," in 5th UPI International Conference on Technical and Vocational Education and Training (ICTVET), 2018. Atlantis Press, Indonesia, 2019. pp. 73-79.

[7] D. N. Binsaif, "The Impact of Roles Overrides in E-Learning Platform on Students Autonomy: The Case of Saudi Electronic University," International Journal of Management, vol. 11, no. 8, pp. 235-244, 2020, [Online]. Available: https://papers.ssrn.com/sol3/papers.cfm?abstract_id=3713796.

[8] Naseej, "Shaqra University Launches MEDAD Cloud Learning Management Platformand its Redesigned Online Portal," Naseej, May 08, 2019. https://www.naseej.com/shaqra-university-launches-medad-cloud-learningmanagement-platform-and-its-redesigned-online-portal/ (accessed Apr. 04, 2021).

[9] M. L. Hung, C. Chou, C. H. Chen, and Z. Y. Own, "Learner readiness for online learning: Scale development and student perceptions," Computers \& Education, vol. 55, no. 3, pp. 1080-1090, Nov. 2010, doi: 10.1016/j.compedu.2010.05.004.

[10] A. A. M. Al-Araibi, M. N. bin Mahrin, R. C. M. Yusoff, and S. Binti Chuprat, "A model for technological aspect of e-learning readiness in higher education," Education and Information Technologies, vol. 24, no. 2, pp. 1395-1431, Nov. 2018, doi: 10.1007/s10639-018-9837-9.

[11] M. A. Almaiah and M. Abdul Jalil, "Investigating Students' Perceptions on Mobile Learning Services," International Journal of Interactive Mobile Technologies (iJIM), vol. 8, no. 4, p. 31, Oct. 2014, doi: 10.3991/ijim.v8i4.3965.

[12] M. A. Almaiah and A. Almulhem, "A conceptual framework for determining the success factors of e-learning system implementation using Delphi technique," Journal of Theoretical and Applied Information Technology, vol. 96, no. 17, pp. 5962-5976, Sep. 2018.

[13] S. P. Kumar, "Impact of Online Learning Readiness on Students Satisfaction in Higher Educational Institutions," Journal of Engineering Education Transformations, vol. 34, Special Issue, pp. 64-70, Jan. 2021, doi: 10.16920/jeet/2021/v34i0/157107.

[14] V. Venkatesh and F. D. Davis, "A Theoretical Extension of the Technology Acceptance Model: Four Longitudinal Field Studies," Management Science, vol. 46, no. 2, pp. 186-204, Feb. 2000, doi: 10.1287/mnsc.46.2.186.11926.

[15] N. Ameen, "Arab users' acceptance and use of mobile phones: a case of young users in Iraq, Jordan and UAE," Doctoral dissertation, Anglia Ruskin University, East Anglia, United Kingdom, 2017.

[16] K. K. T. So and P. Swatman, "The diminishing influence of age and gender on e-learning readiness of teachers in Hong Kong," in Third International Conference on Hybrid Learning, ICHL 2010. Springer, Beijing, China, 2010, pp. 477-488.

[17] M. Cuadrado-García, M. E. Ruiz-Molina, and J. D. Montoro-Pons, "Are there gender differences in e-learning use and assessment? Evidence from an interuniversity online project in Europe," Procedia - Social and Behavioral Sciences, vol. 2, no. 2, pp. 367-371, 2010, doi: 10.1016/j.sbspro.2010.03.027.

[18] F. Kanwal, M. Rehman, and M. A. Malik, "E-Learning Adoption and Acceptance in Pakistan: Moderating Effect of Gender and Experience," April 2020, vol. 39, no. 2, pp. 324-341, Apr. 2020, doi: 10.22581/muet1982.2002.09. 
[19] V. Venkatesh, M. G. Morris, G. B. Davis, and F. D. Davis, "User Acceptance of Information Technology: Toward a Unified View," MIS Quarterly, vol. 27, no. 3, pp. 425-478, 2003, doi: 10.2307/30036540.

[20] M. A. Almaiah, M. A. Jalil, and M. Man, "Preliminary study for exploring the major problems and activities of mobile learning system: A case study of Jordan," Journal of Theoretical \& Applied Information Technology, vol. 93, no. 2, 2016.

[21] S. Alharbi and S. Drew, "Using the Technology Acceptance Model in Understanding Academics' Behavioural Intention to Use Learning Management Systems," International Journal of Advanced Computer Science and Applications, vol. 5, no. 1, pp. 143-155, 2014, doi: 10.14569/ijacsa.2014.050120.

[22] J. Creswell, Research Design: Qualitative, Quantitative, and Mixed Methods Approaches, 4th ed. Thousand Oaks, CA: Sage, 2014.

[23] S. Tuntirojanawong, "Students' Readiness for E-Learning: A Case Study of Sukhothai Thammathirat Open University, Thailand," Journal of Learning in Higher Education, vol. 9, no. 1, pp. 59-66, 2013.

[24] P. R. Hinton, I. McMurray, and C. Brownlow, SPSS Explained, 2nd ed. United Kingdom: Routledge, 2014.

[25] M. M. Moftakhari, "Evaluating E-Learning Readiness of Faculty of Letters of Hacettepe," Master's Thesis, Hacettepe University Social Sciences Institute, Ankara, 2013.

[26] D. Akaslan and E. L. Law, "Measuring teachers' readiness for e-learning in higher education institutions associated with the subject of electricity in Turkey," in 2011 IEEE Global Engineering Education Conference (EDUCON). IEEE, 2011, pp. 481-490.

[27] P. E. Ramírez-Correa, J. Arenas-Gaitán, and F. J. Rondán-Cataluña, "Gender and Acceptance of E-Learning: A Multi-Group Analysis Based on a Structural Equation Model among College Students in Chile and Spain," PLOS ONE, vol. 10, no. 10, pp. 1-17, Oct. 2015, doi: 10.1371/journal.pone.0140460.

\section{BIOGRAPHIES OF AUTHORS}

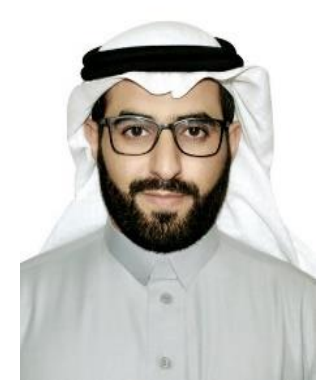

Dr. Raed Shujaa Alotaibi received the B.Sc. degree in Infromation Systems from King Saud University, Saudi Arabia, in 2008, and the M.Sc. degree in Information Systems from Griffith University, Australia, in 2010, and the Ph.D. degree in Information Systems from Griffith University, Australia, in 2018. He is currently an Assistant Professor with Department of Computer Science, Shaqra Community College, Shaqra University, Saudi Arabia. His research interests include new technologies acceptance and adoption (E-business, E-Learning, Egovernment, E-commerce, mobile technologies) and digital transformation.

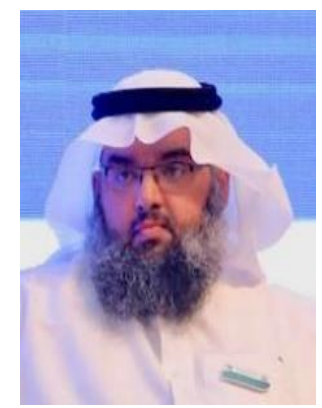

Dr. Abdulrahman Abdullah Alghamdi received his $\mathrm{PhD}$ in 2010 from Heriot watt University- Computer Department, UK. Now he is working as an associate professor and a faculty member at the computer sciences department of Shaqra University's College of Computing and Information Technology (CCIT). He is also the vice dean for development and quality. He has taught several university courses in the computer science field, including computer security, advanced programming, advanced database management systems, and artificial intelligence courses. His research interests include information security, programming, database, image processing. 